\title{
Comparison of the therapeutic effect of the Persian Medicine Protocol with the common treatment of chronic rhinosinusitis: a randomized clinical trial
}

\author{
Majid Anushiravani ${ }^{1}$, Mahdi Bakhshaee ${ }^{2}$, Ali Taghipour ${ }^{3}$, Mohammad Reza Mehri $^{4}$
}

${ }^{1}$ MD. Ph.D. of Persian Medicine, Assistant Professor, Department of Persian Medicine, School of Persian and Complementary Medicine, Mashhad University of Medical Sciences, Mashhad, Iran

${ }^{2}$ MD. Associate Professor, Sinus and Surgical Endoscopic Research Center, Faculty of Medicine, Mashhad University of Medical Sciences, Mashhad, Iran

${ }^{3}$ MD. PhD in Epidemiology, Associate Professor, Department of Epidemiology and Biostatistics, School of Health, Social Determinants of Health Research, Cancer Research Center, Mashhad University of Medical Sciences, Mashhad, Iran

${ }^{4}$ MD. PhD of Persian Medicine, Student Research Committee, School of Persian and Complementary Medicine, Mashhad University of Medical Sciences, Mashhad, Iran

Type of article: Original

\begin{abstract}
Background: Chronic rhinosinusitis is one of the most common diseases affecting the quality of life of patients. Patients suffer from high costs in the diagnosis and treatment of the disease. Frequent recurrence and failure of therapeutic protocols are among the most important issues in the management of this disease. In view of this, the use of traditional and complementary therapies to promote the treatment of this disease has been increasingly taken into account.

Objective: Comparison of the effectiveness of the Persian Medicine Protocol with the conventional therapy in the treatment of chronic rhinosinusitis.

Methods: A randomized clinical trial was conducted at Imam Reza Hospital in Mashhad, Iran from July 2016 to March 2017. For patients with chronic rhinosinusitis symptoms, endoscopy of the sinuses was performed by an ENT specialist and in the case of negative endoscopy, paranasal sinus CT scan was requested. A total of 42 patients with chronic rhinosinusitis were randomly assigned to two groups. The first group (classical) received systemic and intranasal cortisone, and the second group (traditional) received a therapeutic Persian medicine protocol including intranasal lavender oil, and Liquorice Marjoram Tea (L. M. tea) for six weeks. The symptoms of the patients were evaluated using the SNOT-22 questionnaire at the beginning of the study and at the sixth week. If no improvement occurs, treatment continued for 12 weeks. Data were analyzed by SPSS version 16, using ANOVA, independent-samples and paired-samples t-test, Wilcoxon signed-rank test, and simple linear regression.

Results: In 20 patients in the traditional group, the decrease in SNOT score was observed as $56 \%$ after 6 weeks treatment $(\mathrm{p}=0.001)$, which is similar to the effect of the first group (classical). Although there was no statically significant difference between the two groups, in clinical terms, the difference in mean systemic symptoms such as confusion with $1.05(\mathrm{p}=0.5)$ and fatigue with $1.63(\mathrm{p}=0.01)$ had more improvement in the traditional group, and the difference in mean local symptoms such as nasal congestion with $2.37(\mathrm{p}=0.78)$ and runny nose with 1.95 $(\mathrm{p}=0.14)$ had a more decrease in the classical group.

Conclusion: The results of this trial indicate the effectiveness of the Persian Medicine Protocol (including Lavender oil and L.M tea) in the treatment of chronic rhinosinusitis, especially on improving systemic symptoms.
\end{abstract}

\section{Corresponding author:}

Dr. Mohammad Reza Mehri, School of Persian and Complementary Medicine, Mashhad University of Medical Sciences, Mashhad, Iran. Tel: +98.5138848930, Email: mehrimr1@mums.ac.ir

Received: September 05, 2017, Accepted: November 29, 2017, Published: July 2018

iThenticate screening: November 28, 2017, English editing: March 27, 2018, Quality control: March 28, 2018

This article has been reviewed / commented by five experts

Funding / research project approval: 931673 (Mashhad University of Medical Sciences)

Ethics approval: 931673, dated November 07, 2015 (Mashhad University of Medical Sciences)

(C) 2018 The Authors. This is an open access article under the terms of the Creative Commons Attribution-NonCommercialNoDerivs License, which permits use and distribution in any medium, provided the original work is properly cited, the use is non-commercial and no modifications or adaptations are made. 
Nevertheless more clinical studies are necessary to support the acquired results.

Trial registration: This trial was registered at the Iranian Center for Clinical Trials (ID: IRCT2015112425217N1).

Funding: This research is part of a PhD thesis and is funded by the Vice-Chancellor for Research at Mashhad University of Medical Sciences, Grant No. 931673.

Keywords: Rhinosinusitis, Persian medicine, Origanum, Lavender, Licorice

\section{Introduction}

Chronic rhinosinusitis refers to inflammation of the nasal mucosa and sinuses (1) and has several complications (2). Symptoms and signs are divided into two major and minor categories. The disease has a relatively high prevalence (3) and according to some evidence, its incidence and prevalence is increasing (4). The prevalence of this disease worldwide is about $13.5 \%$. (3). The prevalence of this disease is high in Iranian society, as in a meta-analysis study, the rate of sinusitis in Iran of about 53\% (between $40 \%$ and $65 \%$ with a $95 \%$ confidence interval) has been reported (5). However, it seems that this prevalence is more among patients with background illnesses. For example, in an examination of asthmatic patients in Iran, the prevalence of sinusitis in adults was 48.3\% (6), and in children aged 2 to 16 years old $73.2 \%$ (7) has been reported. Chronic rhinosinusitis affects the quality of life, and is comparable to chronic disabling diseases (8) and regarding the burden of the disease and its complications, it is considered as one of the 10 most debilitating diseases (9). Economically, sinusitis treatment is expensive (10), as some studies show that its treatment costs are approximately 1.5 times more than other similar diseases (11). Meanwhile, during the treatment of this disease, there are frequent outpatient visits, numerous diagnostic and therapeutic measures and a reduction in the productivity of the workplace (12). Treatment options for acute and chronic sinusitis are currently proposed, including the use of corticosteroids, antibiotics, antihistamines and, if necessary, surgical procedures for sinuses (13). However, due to the heterogeneous nature of chronic sinusitis, many of these treatments cannot root out its background cause (14). In addition, in a number of patients who have been treated repeatedly with antibiotics or sinus surgery, there is an increased risk of colonization of antibiotic-resistant pathogens and surgical complications (1). The incidence of chronic rhinosinusitis after endoscopic surgery has been reported to be $60 \%$, with $47 \%$ of them requiring re-surgical operation (15). Due to the low level of treatment in this disease and frequent recurrence, the use of traditional and complementary medicine is common (16), with about one third of patients with chronic rhinosinusitis using plant compounds to fix their problem (17). According to previous studies in Iran, one of the most common causes for referring to traditional medicine clinics was sinusitis (18). However, in the reported evidence, the effectiveness of medicinal plants in the treatment of chronic sinusitis is limited (19), but several studies have been conducted in relationship with using various medicinal herbs, including: Rumex patientia (Garden patience), Ecballium elaterium (Squirting cucumber), Stachys schtschegleevii (Poulk), Pelargonium sidoides (African geranium) (20-22). On the other hand, in the Persian medicine literature, a disease called "NAZLA" is mentioned whose symptoms and signs are compatible with chronic rhinosinusitis (23), and for which, various therapies have been mentioned (24). The main objective of this study was to determine the effectiveness of the Persian-based therapeutic protocol on chronic rhinosinusitis compared with classical drug therapy, and its specific objectives were the following: Determination of the effectiveness of the Persian Medicine Protocol in the treatment of chronic sinusitis based on the SNOT-22 test, determining the effectiveness of classical medicine in the treatment of chronic sinusitis according to the SNOT-22 test, and finally comparing the effectiveness of the Persian Medicine Protocol with conventional therapy for the treatment of chronic sinusitis, based on the SNOT-22 test. In this regard, the researchers have attempted to design and implement a clinical trial study of the effects of lavender, marjoram and licorice plants on chronic rhinosinusitis.

\section{Material and Methods}

\subsection{Research design}

This study was a randomized, single-blind clinical trial on patients with chronic rhinosinusitis from July 2016 to March 2017.

\subsection{Population studied}

The population under study was people with chronic rhinosinusitis and the statistical sample included individuals with chronic rhinosinusitis symptoms referring to the specialized centers of ENT and the Persian medicine of Imam Reza Hospital, a recessive center affiliated to Mashhad University of Medical Sciences (MUMS) in northeastern Iran. Patients with typical symptoms of chronic rhinosinusitis (based on the latest diagnostic criteria for chronic rhinosinusitis [AAO-HNS] in the United States of America in 2015) with the diagnosis of ENT, were examined by 
endoscopic sinuses or spinal paranasal sinus $\mathrm{CT}$ scans and entered the research plan if they had entry criteria (Figure $1)$.

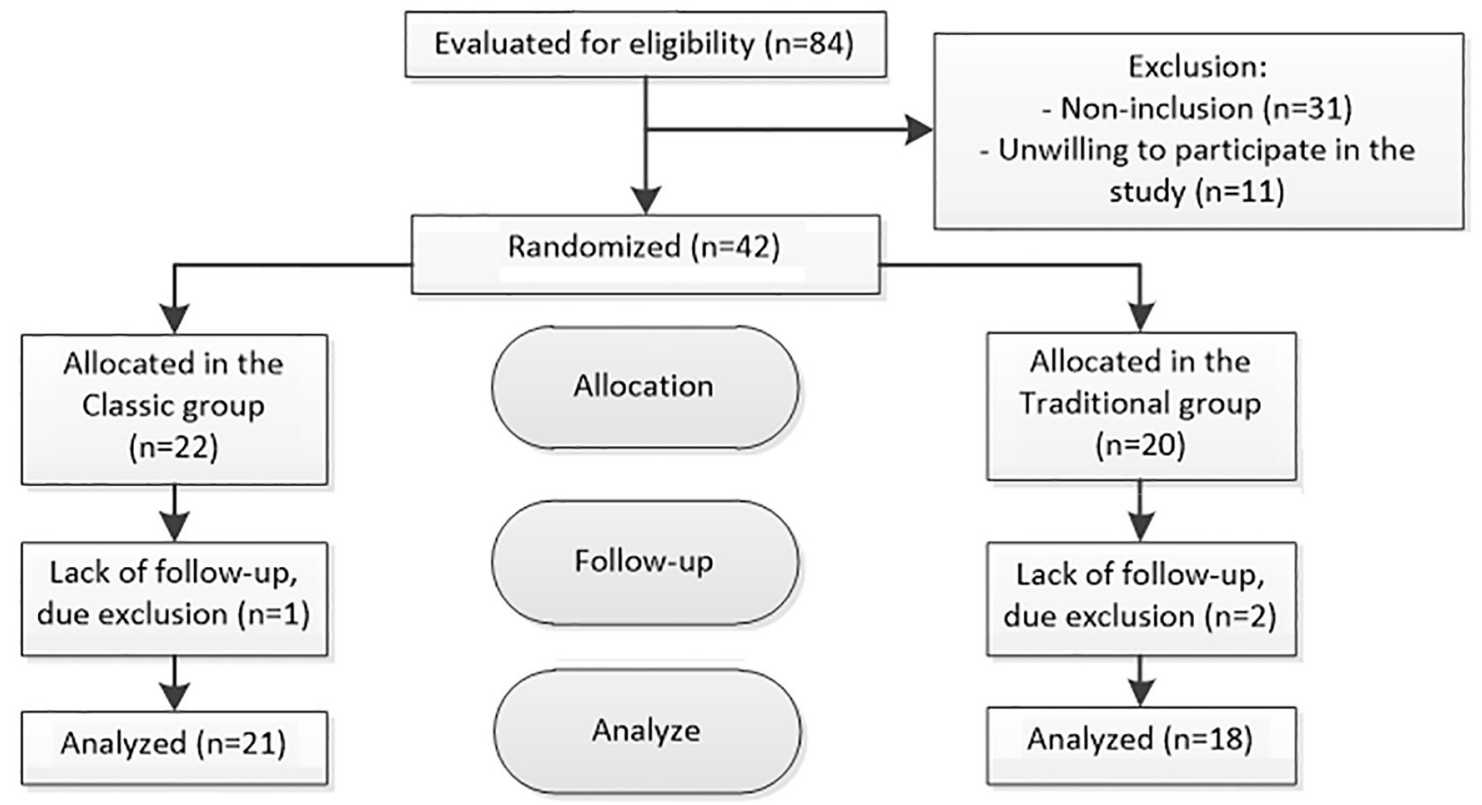

Figure 1. Flowchart of the clinical trial based on CONSORT

\subsection{Entry and exit criteria}

The following cases were considered as inclusion criteria: aged 18 to 50 years, having at least two signs of symptoms: Mucosal septic secretion (anterior, posterior, or both), nasal obstruction (congestion), pain, pressure, decreased sense of smell, the presence of the above symptoms for at least 12 weeks, proven inflammation with at least one of the following ways: Observing mucosal septic secretions (non-transparent) or edema in the middle meatus or anterior region of ethmoid, the presence of polyps in the nasal cavity or middle meatus, or radiological imaging indicating inflammation in the paranasal sinuses. Exit criteria included chronic sinusitis with acute infection of respiratory microbial infections, chronic sinusitis associated with anatomical obstruction requiring surgery, sensitivity or contraindication to the components of the drug combination of traditional and Persian medicine in patients, pregnancy, immunodeficiency or history of hypertension.

\subsection{Interventions}

Patients who had inclusion criteria were randomly assigned to traditional and classical groups, and questionnaires of demographic and clinical information were completed. Each group was treated in parallel with one of two treatments in the following way: 1) Patients in the classical group (control group), inhaler corticosteroid (flixonase), received 2 puffs per day, plus daily nasal washings with normal saline serum at two times in the morning and at night. In cases of no recovery, systemic corticosteroid (as prednisone tablets at a dose of $1 \mathrm{mg} / \mathrm{kg}$ ) that was tapered within 5 days was prescribed; 2) Patients in the traditional group (intervention group) received L.M tea as a combination of 5gram packs containing 2 grams of Licorice root (Glycyrrhiza glabra) and 3 grams of Marjoram leaves (Origanum vulgare). The patient adds the contents of each package to $200 \mathrm{cc}$ of boiling water which is steeped for 20 minutes and then filtered. Consumption, was three times an hour after food, in a lukewarm and sipping manner. In addition, an intranasal oily product was prepared for these patients. Patients in the intervention group dropped this oil locally up to 2-3 drops per nostril every night before bedtime. The method of preparation of this oil was 3 weeks maceration of lavender (Lavandula angustifolia) flower in pure olive oil. The method of oil extraction was based on the sources of Persian medicine. According to this instruction, to get the oil of the flowers, they should be put in oil and placed in an appropriate place (such as the sunlight), and once a week (for up to three weeks) they should be cleaned and refilled (25). For this purpose, 20 grams of lavender flowers were placed inside a beaker containing $300 \mathrm{cc}$ of olive oil (Extra virgin type, Minodasht brand), so that about one third of the beaker contained only olive oil without lavender. After 10 days of initial immersion, all the lavender flowers of the above composition were separated from the oil first by metallic filter and then by sterilized gauze, and again, the same amount of lavender flower was added to the remaining oil, and then immersed. After 10 days from the second immersion, the plant mass was isolated by 
using sterile gauze and under pressure, and the obtained oil was poured into 15 centrifuge tubes and centrifuged for 20 minutes at $3000 \mathrm{rpm}$. Two grams of licorice and three grams of marjoram were packed in nylon bags and were ready to be delivered to the patients after labeling. The originality of the plants used in this study was confirmed by a botanical expert of the Plant Sciences Research Center of Ferdowsi University of Mashhad (Herbarium Numbers 14328 and 14261 belonging to marjoram and licorice, respectively).

\subsection{Outcomes}

Based on the Persian version of the SNOT-22 questionnaire whose validity and reliability was confirmed by Jalessi et al. (2013), (Cronbach's Alpha coefficient $=0.898)(26)$, the change in the score of the questionnaire and each single symptom was considered as the primary outcome, and the symptom recovery time was also considered as the secondary outcome. The SNOT-22 questionnaire contains 22 questions. These questions relate to the prominent features of the nose and throat (such as nasal congestion, runny nose), localized non-nasal symptoms (such as pain and fullness of ear), symptoms associated with sleep quality (such as difficulty falling asleep) and general symptoms (such as fatigue and dizziness). Question scores vary based on six degrees (from 0 to 5). The SNOT-22 questionnaire was filled at the beginning of the study (week zero) and the end of the week 6 and evaluated for changing the severity of the symptoms. The treatment was stopped for patients who had clinical symptom relief and patients with all or part of the symptoms were treated for 12 weeks. Finally, the SNOT-22 questionnaire was completed for them. In case of possible complications, the patient was registered in the relevant form and in case of severe complication the patient was excluded from the study.

\subsection{Sample size}

With the help of the PASS software and based on the $90 \%$ confidence estimate for the difference between the mean scores of the SNOT-22 questionnaire, with an error estimation of 8 scores and a standard deviation of 15 for both groups, the sample size was considered to be 20 in each group with a $10 \%$ drop in each group, 22 samples were selected.

\subsection{Allocation, blinding and randomization}

Patients who had the criteria for entering the study were randomly assigned to traditional and classical groups and demographic information questionnaires were filled out with clinical information. Each group was treated with one of two treatments in parallel. Due to the difference in the type of drug interventions and how it was used in two groups that were differentiated by patients, blindness was not possible in this regard. But each patient was unaware of the treatment received by other participants in the study, and the analyst was not aware of the results of the patients. Therefore, this study was done randomly and single blind.

\subsection{Statistical analysis}

Data were entered into the computer after evaluation and analyzed by SPSS software version 16. At first, the characteristics of each group based on descriptive statistical methods including central indices, distribution and frequency distribution were studied and described. Then, for quantitative variables, the normality of their distribution was first measured using the Kolmogorov-Smirnov test. Data were analyzed using independent and paired-samples t-test, repeated measures (ANOVA), Wilcoxon signed-rank test, and simple linear regression. In all calculations, $\alpha 0.05$ was considered as the significant level.

\subsection{Ethics of research}

The present study has been approved by the Ethics Committee for Research at Mashhad University of Medical Sciences (Ref: 931673, dated November 07, 2015). Patients were informed about this study and signed the consent form individually. Participation was completely voluntary and participants were allowed to leave at any time. In order to ensure that no financial, mental or physical harm occurred to the participants, an accessible telephone number was provided to contact at any time if information on the research or medical assistance was required. All participants' data were received and kept confidential.

\section{Results}

\subsection{Entry, screening and completing intervention}

During the period from July 2016 to March 2017, 86 patients with symptoms of chronic rhinosinusitis referred to the specialized otorhinolaryngology and Persian medicine clinics of Imam Reza Hospital in Mashhad. Of these patients, after examination by an ENT, and performing endoscopic sinuses or CT scan of paranasal sinuses, 42 patients who were diagnosed with chronic rhinosinusitis were eligible to enter the trial. During the clinical trial, 2 patients in the 
group were treated with traditional medicine due to complications (one due to hypertension and another for the exacerbation of symptoms) failed to complete the treatment process, and 1 patient from the classical medicine department (due to the lack of recovery of symptoms leading to surgery) failed to complete the treatment.

\subsection{Demographic findings}

The mean age of participants in the study was 38.86 years with a standard deviation of 10.35 . Of the patients studied, $64.3 \%$ were male and $35.7 \%$ were female. A total of $59.5 \%$ of the participants in the study had university education and the rest had lower qualifications. Furthermore, $76.2 \%$ of the patients in the project were employed (Table 1).

Table 1. Demographic information of the participants

\begin{tabular}{|l|l|l|l|}
\hline Variable & $\mathrm{n}$ & $\%$ \\
\hline Sex & Male & 27 & 64.3 \\
\cline { 2 - 4 } & Female & 15 & 35.7 \\
\hline \multirow{5}{*}{ Education } & Illiterate & 2 & 4.8 \\
\cline { 2 - 4 } & Primary School & 4 & 9.5 \\
\cline { 2 - 4 } & Secondary School & 6 & 14.3 \\
\cline { 2 - 4 } & High School & 5 & 11.9 \\
\cline { 2 - 4 } & University & 25 & 59.5 \\
\hline \multirow{5}{*}{ Employment } & Working & 32 & 76.2 \\
\cline { 2 - 4 } & Workless & 10 & 23.8 \\
\hline Marital status & Yes & 37 & 88.1 \\
\cline { 2 - 4 } & No & 5 & 11.9 \\
\hline \multirow{2}{*}{ Smoking } & Yes & 3 & 7.3 \\
\cline { 2 - 4 } & No & 38 & 92.7 \\
\hline
\end{tabular}

\subsection{Intervention findings}

In paraclinical examination, $82 \%$ of patients had endoscopic evidence of chronic rhinosinusitis. Also, in $81 \%$ of patients, chronic rhinosinusitis was found in paranasal sinus CT scans. Among the criteria for diagnosis of chronic rhinosinusitis, based on the American Academy of Otorhinolaryngology and the American Academy of Neck Surgery (AAO-HNS), all patients had nasal congestion or nasal-anterior or posterior secretion (100\% of cases), however, pain or pressure in the face, and reduced or absent olfaction were reported from $78.6 \%$ and $85.7 \%$ of patients, respectively. Kolmogorov Smirnov test was used to check the normality of the quantitative variables used in the study. The results finally showed that all the variables used in the study had normal distribution. In examining the SNOT scores in the two traditional and classical groups whose results are presented in Table 2, SNOT scores were not significantly different in the two groups in the three stages of follow-up, but in analyzing the effect of intervention by group analysis, variance analysis showed that the scores were significantly different during the three stages. On the other hand, as shown in Table 3, comparison of SNOT scores in the third monitoring (the $12^{\text {th }}$ week treatment $)$ with the second monitoring $\left(6^{\text {th }}\right.$ weeks treatment $)$ indicates a decrease in the SNOT score in the traditional group and increase in the classical group. The evaluation of classified SNOT scores in both groups before and after intervention, as shown in Table 3, indicates that SNOT scores vary in both groups before and after intervention and the severity of symptoms in both groups decreased after intervention, especially as the percentage of "very severe" stage was much less than "very mild" stage, and this decrease in intensity from stage 3 is very tangible. Table 4 compares the single marker of patients' symptoms before and after intervention in comparing the two treatment groups.

Table 2. Mean and standard deviations of SNOT scores by groups

\begin{tabular}{|l|l|l|l|}
\hline $\begin{array}{l}\text { Follow up level based } \\
\text { on SNOT }\end{array}$ & $\begin{array}{l}\text { Traditional group (Mean } \pm \\
\text { SD) }\end{array}$ & Classic group (Mean \pm SD) & $\begin{array}{l}\text { Results of Independent- } \\
\text { samples t-test }\end{array}$ \\
\hline SNOT 1 & $48.31 \pm 18.78$ & $48.29 \pm 14.7$ & $\mathrm{t}=-0.002 ; \mathrm{p}$-value $=0.998$ \\
\hline SNOT 2 & $21.31 \pm 12.57$ & $22.57 \pm 9.29$ & $\mathrm{t}=0.147 ; \mathrm{p}$-value $=0.884$ \\
\hline SNOT 3 & $15.25 \pm 12.46$ & $28.71 \pm 20.68$ & $\mathrm{t}=1.94 ; \mathrm{p}$-value $=0.065$ \\
\hline Result of the ANOVA & $\mathrm{F}=33.07 ; \mathrm{p}$-value $<0.001$ & $\mathrm{~F}=17.42 ; \mathrm{p}$-value $<0.001$ & - \\
\hline
\end{tabular}

SNOT 1: SNOT scores at the patient's admission, SNOT 2: SNOT scores in the second checking (sixth week of treatment), SNOT 3: SNOT scores in the final checking (12 $2^{\text {th }}$ week of treatment) 
http://www.ephysician.ir

Table 3. Frequency and percentage of groups before and after intervention

\begin{tabular}{|c|c|c|c|c|}
\hline Group & $\begin{array}{l}\text { Severity of rhinosinusitis } \\
\text { according to SNOT score }\end{array}$ & $\begin{array}{l}\text { Percent before } \\
\text { intervention }\end{array}$ & $\begin{array}{l}\text { Percent in the } \\
\text { first follow up }\end{array}$ & $\begin{array}{l}\text { Result of Wilcoxon } \\
\text { signed-rank test }\end{array}$ \\
\hline \multirow[t]{5}{*}{ Traditional } & 1 (Very mild problem) & 15 & 60 & \multirow{5}{*}{$\begin{array}{l}Z=-3.12 ; p \text {-value }= \\
0.002\end{array}$} \\
\hline & 2 (Mild or slight problem) & 35 & 30 & \\
\hline & 3 (Moderate problem) & 40 & 5 & \\
\hline & 4 (Severe problem) & 10 & 0 & \\
\hline & 5 (Problem as bad as it can be) & 0 & 0 & \\
\hline \multirow[t]{5}{*}{ Classic } & 1 (Very mild problem) & 9.1 & 68.2 & \multirow{5}{*}{$\begin{array}{l}Z=-3.78 ; p- \\
\text { value }<0.001\end{array}$} \\
\hline & 2 (Mild or slight problem) & 50 & 27.3 & \\
\hline & 3 (Moderate problem) & 36.4 & 4.5 & \\
\hline & 4 (Severe problem) & 4.5 & 0 & \\
\hline & 5 (Problem as bad as it can be) & 0 & 0 & \\
\hline
\end{tabular}

Table 4. Comparison of treatment response on the symptoms of patients before and after intervention in each group

\begin{tabular}{|l|l|l|l|l|l|l|l|l|}
\hline \multirow{2}{*}{ Symptom } & \multicolumn{2}{l}{$\begin{array}{l}\text { Mean before intervention (Mean } \pm \\
\text { SD) }\end{array}$} & \multicolumn{2}{l}{$\begin{array}{l}\text { Mean after intervention (Mean } \pm \\
\text { SD) }\end{array}$} & \multicolumn{2}{l|}{ Mean difference } \\
\cline { 2 - 10 } & Traditional & Classic & p-value & Traditional & Classic & Value & Traditional & Classic \\
\hline Need to blow nose & $2.68 \pm 1.6$ & $2.59 \pm 1.5$ & 0.85 & $1.68 \pm 1.1$ & $0.82 \pm 1.2$ & 0.02 & 1 & 1.77 \\
\hline Blockage / congestion of nose & $3.32 \pm 1.2$ & $4.14 \pm 1$ & 0.24 & $1.63 \pm 1.2$ & $1.77 \pm 1.9$ & 0.78 & 1.69 & 2.37 \\
\hline Sneezing & $1.58 \pm 1.3$ & $1.32 \pm 1.6$ & 0.58 & $0.47 \pm 0.6$ & $0.45 \pm 1$ & 0.94 & 1.11 & 0.87 \\
\hline Runny nose & $2.47 \pm 1.4$ & $2.77 \pm 1.6$ & 0.54 & $1.47 \pm 1.5$ & $0.82 \pm 1.2$ & 0.14 & 1 & 1.95 \\
\hline Cough & $1.89 \pm 1.3$ & $1.73 \pm 1.7$ & 0.73 & $0.74 \pm 1$ & $0.5 \pm 0.8$ & 0.43 & 1.15 & 1.23 \\
\hline Post nasal discharge & $3.73 \pm 1.2$ & $3.36 \pm 1.4$ & 0.70 & $1.48 \pm 1.1$ & $1.18 \pm 1.2$ & 0.86 & 2.25 & 2.18 \\
\hline Thick nasal discharge & $3.16 \pm 1.5$ & $2.77 \pm 1.6$ & 0.44 & $1.21 \pm 0.91$ & $0.91 \pm 1$ & 0.34 & 2.95 & 1.86 \\
\hline Ear fullness & $1 \pm 1.5$ & $1.32 \pm 1.6$ & 0.48 & $0.58 \pm 1$ & $0.14 \pm 0.3$ & 0.07 & 0.42 & 1.18 \\
\hline Dizziness & $1.58 \pm 1.38$ & $0.86 \pm 0.88$ & 0.06 & $0.53 \pm 0.9$ & $0.36 \pm 0.8$ & 0.5 & 1.05 & 0.5 \\
\hline Ear pain & $0.63 \pm 0.8$ & $0.46 \pm 0.8$ & 0.5 & 0 & $0.14 \pm 0.3$ & 0.99 & 0.63 & 0.32 \\
\hline Facial pain / pressure & $2.68 \pm 1.7$ & $1.77 \pm 1.5$ & 0.08 & $1.16 \pm 1.3$ & $0.68 \pm 1.2$ & 0.24 & 1.52 & 1.09 \\
\hline Sense of smell / taste & $2.84 \pm 1.7$ & $3.86 \pm 1.5$ & 0.05 & $2.32 \pm 2.1$ & $2.18 \pm 1.9$ & 0.83 & 0.52 & 1.68 \\
\hline Difficulty falling asleep & $1.21 \pm 1.7$ & $2.23 \pm 1.9$ & 0.91 & $0.26 \pm 0.7$ & $0.86 \pm 1.2$ & 0.07 & 0.95 & 1.37 \\
\hline Waking up at night & $1 \pm 1.5$ & $2.36 \pm 2$ & 0.02 & $0.37 \pm 0.8$ & $0.68 \pm 1.1$ & 0.33 & 0.63 & 1.68 \\
\hline Lack of a good night's sleep & $1.89 \pm 1.7$ & $2.23 \pm 1.9$ & 0.57 & $0.26 \pm 0.9$ & $0.41 \pm 0.9$ & 0.62 & 1.63 & 1.82 \\
\hline Waking up tired & $2.11 \pm 1.8$ & $2.09 \pm 1.9$ & 0.98 & $0.89 \pm 1$ & $0.82 \pm 1$ & 0.81 & 1.22 & 1.27 \\
\hline Fatigue & $2.79 \pm 1.1$ & $1.95 \pm 1.4$ & 0.83 & $1.16 \pm 0.8$ & $0.5 \pm 0.7$ & 0.01 & 1.63 & 1.45 \\
\hline Reduced productivity & $2.47 \pm 1.5$ & $1 \pm 1.2$ & 0.002 & $0.68 \pm 1$ & $0.41 \pm 0.7$ & 0.33 & 1.79 & 0.59 \\
\hline Reduced productivity & $2.63 \pm 1.5$ & $1.14 \pm 1.3$ & 0.002 & $0.95 \pm 1$ & $0.45 \pm 0.8$ & 0.1 & 1.68 & 0.69 \\
\hline Frustrated / restless / irritable & $2.42 \pm 1.6$ & $1.55 \pm 1.4$ & 0.08 & $0.74 \pm 0.9$ & $0.45 \pm 0.7$ & 0.3 & 1.68 & 1.1 \\
\hline Sad & $2 \pm 1.5$ & $0.68 \pm 1.1$ & 0.003 & $0.32 \pm 0.7$ & $0.36 \pm 0.7$ & 0.04 & 1.68 & 0.32 \\
\hline Embarrassed & $1.05 \pm 1.5$ & $0.32 \pm 1$ & 0.08 & $0.26 \pm 0.7$ & 0 & 0.1 & 0.79 & 0.32 \\
\hline & & & & & & & \\
\hline
\end{tabular}

\section{Discussion}

The results of this trial showed that the treatment protocol based on Persian medicine, including the lavender oil, along with L.M tea, could be effective in treating patients with chronic rhinosinusitis and its effects on reducing or eliminating the 22-digit symptoms in the SNOT22 questionnaire are similar to the therapeutic effect of the current protocol of classic medicine. Comparing the scores of SNOT items between the traditional and classical groups also showed three categories of results: Accordingly, the symptoms of the first category (which didn't show statistical or clinical difference between two groups) were sneezing, coughing, ear pain, fatigue after sleep, disappointment, restlessness, and irritability. In the second category of symptoms, there were fatigue and sadness, which both were clinically and statistically lower in the traditional group than the classical, and this difference was statistically significant. In the case of "sadness", there was a significant improvement in the severity of symptoms in the traditional group compared with classical, while the difference was statistically significant. Of course, in the case of the sign "blowing the nose", this difference was significant in favor of classical treatment. In addition to the above 
symptoms, 13 other symptoms are classified in the third category, showing a notable difference in the severity of post-treatment symptom between the traditional and classical groups, but this difference is not statistically significant. Accordingly, all of the local symptoms of the nasal cavity (including nasal secretion, nasal congestion, decreased olfactory sensation and post nasal discharge), with the exception of reduced thickness of nasal secretions, which responded better to classical treatment, although it was not statistically significant. But systemic symptoms of patients, with the exception of the difficulty of falling asleep (including confusion, waking up and not having a good night's sleep, decreased efficacy, decreased focusing and embarrassment), better responded to traditional treatment and, despite not being statistically significant, compared to the classical treatment group, were more decreased.

Regarding the higher clinical improvement of systemic symptoms in response to traditional treatment, it can be preferable in some instances. For example, in a patient with the prolonged period of rhinosinusitis and recurrence after treatment with classical treatments, the use of a full 12-week course of treatment with the traditional protocol may be more appropriate; while, in a patient who recently had chronic rhinosinusitis or no resistance and has no long-term desire for treatment, any of the protocols in classical medicine or traditional medicine, depending on the patient's preference, can be selected. Few studies have been done about the effects of the plants used in the present clinical trial (i.e. licorice, marjoram, lavender and olive oil). Madani et al. studied the effect of marjoram on 32 patients (compared with 32 controls) in a randomized, double-blind clinical trial (27). Based on this study, all symptoms of the patients, including headache, nasal congestion, sinus pain, throat secretions, etc. (except reduction of sense of smell and nasal secretion) were found to be remarkably decreased (27), which is similar to the effects observed in our research. In a study by Neher et al., several oily extracts were tested on the ciliary movement of nasal mucosa, and concluded that some herbal remedies, including lavender oil, could increase the ciliary beat frequency (CBF), which its impairment leads to chronic rhinosinusitis (28). The antimicrobial, anti-inflammatory, augmentative, and mucosal effects that can be effective in the treatment of chronic rhinosinusitis are reported in each of the above plants (whose major active ingredients are listed in Table 5). In a study by Giovannini et al. on the effect of Lavandula angustifolia essential oil on macrophage reaction from Staphylococcus aureus infection, this essential oil increased phagocytosis speed and increased the defense of intracellular antibacterial activity by macrophages (29). Another study by Ozogul on a number of herbal essential oils affecting food-borne pathogens showed that lavender essential oil can be effective as an antimicrobial against these pathogens (30). Prusinowska et al. also reported antimicrobial and antioxidant properties in lavender (31). These antimicrobial effects may confirm the findings of the present study on the local use of lavender oil in the pathophysiology of microbial contamination. In another study, conducted by Georgiev et al. on the lavender immune effects, lavender flowers contain polysaccharides that are immune-augmenter and can protect immune deficiencies (32). In a similar study, Gostner et al. concluded in a laboratory study that the effects of lavender on the immune system and neuroendocrine were due to its effect on tryptophan metabolism (33). Of course, in studies of short-term exposure to lavender through inhalation of oil, no significant changes were observed in immunological parameters (such as interleukins 6 and 10) $(34,35)$. In the case of olive oil, although some studies indicate its anti-inflammatory effects in topical use (36), most studies have shown antimicrobial effects $(37)$, immunosuppressive $(38,39)$ and antioxidant $(40-43)$ effects on systemic use.

Table 5. Major active ingredients in plants used in the study

\begin{tabular}{|l|l|}
\hline Medicinal plant & Active ingredients \\
\hline Lavandula angustifolia & Linalool, Linalyl acetate, Tannins, Hydroxcoumarins, Caffeic acid \\
\hline Glycyrrhiza glabra & Triterpene saponins, Flavonoids, Isoflavonoids, Hydroxycoumarins, Steroids \\
\hline Origallum vulgare & Volatile oil (carvacrol, gamma-terpinene, p-cymene), Flavonoids, Caffeic acid \\
\hline Olea europaea & Chieffatty acids (oleic acid, palmitic acid, linoleic acid), Steroids, Tocopherols \\
\hline
\end{tabular}

The study of the use of marjoram in the treatment of sinusitis, with the exception of the study by Madani et al., did not show any results. However, antibacterial effects (44-46), antifungal $(47,48)$, and antioxidant (49) of this plant have been evaluated and shown to be positive. Licorice also has showed anti-viral (50), antibacterial (51), antifungal (52), anti-oxidant (53), anti-inflammatory $(54,55)$ and immune enhancer (56) effects in various research but based on the studied articles, it hasn't been used directly in the treatment of chronic sinusitis. In addition to the above mentioned findings about the effectiveness of the plants used in the current trial, teachings in Persian Medicine Literature also reveals significant effects in justifying its usage for rhinosinusitis. Among the writings of Bu-Ali Sina in the Book of Law, he attributes the effects of breakdown of waste materials and the opening of obstruction to marjoram (57), and Hakim Jorjani regards it as a treatment for nasal congestion (58). Among the effects of licorice in these books is the excretion of thick mucus (59). The therapeutic effects of lavender on NAZLA have been 
mentioned in Persian medicine books (60) and its use has been shown to enhance brain functions and improve mental status (61). Considering the above points, it might be possible to justify the better result of Persian protocol in reducing systemic symptoms of patients, and in patients with prolonged recurrence, reduced mental and emotional functioning, and reduced social and occupational activity due to chronic rhinosinusitis, this therapy package is preferred.

\section{Limitations}

The main limitation of the present study was the lack of ease of use of an oral remedy in Persian medicine compared to common forms. From the phytochemical point of view, due to the use of four different herbs, it is not possible to attribute the effects of the research to a particular active ingredient or at least a certain plant.

\section{Conclusions}

In summary, the present study showed that a therapeutic package based on Persian medicine can be effective in the treatment of chronic rhinosinusitis, and in addition, it would promote systemic symptoms, especially the symptoms of subjective emotional and social efficacy, more than classical treatment.

\section{Trial registration:}

This trial has been registered with IRCT ID: IRIC IRCT2015112425217N1 at the Iranian Center for Clinical Trials.

\section{Acknowledgment and funding:}

This article is the result of the support of the Research Vice-Chancellor of Mashhad University of Medical Sciences from the Ph.D. Student's Thesis, No. 931673, which is hereby commended and appreciated.

\section{Conflict of Interest:}

There is no conflict of interest to be declared.

\section{Authors' contributions:}

All authors contributed to this project and article equally. All authors read and approved the final manuscript.

\section{References:}

1) Fauci A, Braunwald E, Kasper D, Hauser S, Longo D, Jameson J, et al. Harrison's Principles of Internal Medicine. 17th Edition: Mcgraw-hill; 2008

2) Oxford LE, McClay J. Complications of acute sinusitis in children. Otolaryngology-Head and Neck Surgery. 2005; 133(1): 32-7. doi: 10.1016/j.otohns.2005.03.020. PMID: 16025049.

3) Durr DG, Desrosiers MY, Dassa C. Impact of rhinosinusitis in health care delivery: the Quebec experience. The Journal of otolaryngology. 2001; 30(2): 93-7. PMID: 11770963

4) Benninger MS, Ferguson BJ, Hadley JA, Hamilos DL, Jacobs M, Kennedy DW, et al. Otolaryngology Head and Neck Surgery. 2003; 129(3, Supplement): S1-32.

5) Andy SA, Sarookhani D, Tavirany MR. Prevalence of Sinusitis in Iran: a systematic review and metaanalysis study. Der Pharmacia Lettre. 2016; 8(5): 31-9.

6) Safari M, Mohebbi N. Assessment of the prevalence of sinusitis in children under the age of 12 years with asthma in Hamedan. The Iranian Journal of Otorhinolaryngology. 2010; 21(3): 133-8.

7) Ehsanipour F, Javaher Tarash N, Pirdehghan A. The Prevalence of Sinusitis in Young Asthmatic Patients(2-16y) Referred to Rasoul-e-Akram Hospital During 1993-2003. RJMS. 2005; 12(45): 31-6.

8) Gliklich RE, Metson R. The health impact of chronic sinusitis in patients seeking otolaryngologic care. Otolaryngology-Head and Neck Surgery. 1995; 113(1): 104-9. doi: 10.1016/S0194-5998(95)70152-4.

9) Goetzel RZ, Hawkins K, Ozminkowski RJ, Wang S. The health and productivity cost burden of the" top 10" physical and mental health conditions affecting six large US employers in 1999. Journal of occupational and environmental medicine. 2003; 45(1): 5-14. doi: 10.1097/00043764-200301000-00007. PMID: 12553174.

10) Anand VK. Epidemiology and economic impact of rhinosinusitis. Annals Of Otology Rhinology And Laryngology. 2004; 113(5): 3-5. doi: 10.1177/00034894041130S502. PMID: 15174752.

11) Chung SD, Hung SH, Lin HC, Lin CC. Health care service utilization among patients with chronic rhinosinusitis: a population-based study. The Laryngoscope. 2014; 124(6): 1285-9. doi: 10.1002/lary.24500. PMID: 24338913. 
12) Van Crombruggen $K$, Zhang N, Gevaert P, Tomassen $P$, Bachert C. Pathogenesis of chronic rhinosinusitis: inflammation. J Allergy Clin Immunol. 2011; 128(4): 728-32. doi: 10.1016/j.jaci.2011.07.049. PMID: 21868076.

13) Fokkens WJ, Lund VJ, Mullol J, Bachert C, Alobid I, Baroody F, et al. EPOS 2012: European position paper on rhinosinusitis and nasal polyps 2012. A summary for otorhinolaryngologists. Rhinology. 2012; 50(1): 1-12. doi: 10.4193/Rhino50E2. PMID: 22469599.

14) Probst R, Grevers G. Basic Otorhinolaryngology: A Step-by-Step Learning Guide: Thieme; 2011.

15) Wynn R, Har - El G. Recurrence rates after endoscopic sinus surgery for massive sinus polyposis. The Laryngoscope. 2004; 114(5): 811-3. doi: 10.1097/00005537-200405000-00004. PMID: 15126735.

16) Rotenberg BW, Bertens KA. Use of complementary and alternative medical therapies for chronic rhinosinusitis: a canadian perspective. J Otolaryngol Head Neck Surg. 2010; 39(5): 586-93. PMID: 20828524.

17) Hatipoğlu U, Rubinstein I. Anti-inflammatory treatment of chronic rhinosinusitis: a shifting paradigm. Current allergy and asthma reports. 2008; 8(2): 154-61. doi: 10.1007/s11882-008-0026-6. PMID: 18417058 .

18) Hozni S, Azmiyan Moghadam F, Yeganeh M, Haghshenas S. Evaluation of Demographic Characteristics and Attitudes about Traditional Medicine among Patients Refered to a Clinic. Journal of Guilan University of Medical Sciences. 2015; 24(94): 72-9.

19) Guo R, Canter PH, Ernst E. Herbal medicines for the treatment of rhinosinusitis: a systematic review. Otolaryngology-Head and Neck Surgery. 2006; 135(4): 496-506. doi: 10.1016/j.otohns.2006.06.1254. PMID: 17011407.

20) Ghazi-Moghadam K, Inançlı HM, Bazazy N, Plinkert PK, Efferth T, Sertel S. Phytomedicine in Otorhinolaryngology and Pulmonology: Clinical Trials with Herbal Remedies. Pharmaceuticals. 2012; 5(8): 853-74. doi: 10.3390/ph5080853. PMID: 24280678, PMCID: PMC3763668.

21) Chitsaz M, Mohammadi H, N M, Kamalinejad CE, and others. Anti-bacterial effects of the plant Polk (Stachys schtschegleevii) in vitro (2007); Bimonthly Journal of Shahed University, Issue 67

22) Süleyman H, Demirezer LÖ, Kuruüzüm A, Banoğlu Z, Göçer F, Özbakir G, et al. Antiinflammatory effect of the aqueous extract from Rumex patientia roots. Journal of ethnopharmacology. 1999; 65(2): 141-8. doi: 10.1016/S0378-8741(98)00175-5.

23) Elahi H, Masroorchehr MR, Nemati S, Kamalinejad M, Besharat M, Hajimehdipoor H, et al. Historical Applications of Nigella sativa L.(Black cumin) in the Treatment of Zokam and Nazleh in Persian Medicine. Journal of Research on History of Medicine. 2014; 3(1): 11-20.

24) Avicenna H. Ghanoon fe teb. Beirut: Aljoze Sales. Darolhaya Altras Alarabi. 2004: 413.

25) Aghili Khorasani MH. Gharabadin e kabir (persian). Qom: Noor e vahy; 2011: 954.

26) Jalessi M, Farhadi M, Kamrava SK, Amintehran E, Asghari A, Rezaei Hemami M, et al. The Reliability and Validity of the Persian Version of Sinonasal Outcome Test 22 (Snot 22) Questionnaires. Iranian Red Crescent Medical Journal. 2013; 15(5): 404-8 doi: 10.5812/ircmj.7937. PMID: 24349728, PMCID: PMC3838650.

27) Madani S, Kousarian M, Khalilian A, Rabiei K, Azadbakht M. Origanum Vulgar Inhaler in The Treatment of Chronic Rhinosinositis, A Double Blind Placebo Controlled Randomized Clinical Trial. Journal of Mazandaran University of Medical Sciences. 2007.

28) Neher A, Gstottner M, Thaurer M, Augustijns P, Reinelt M, Schobersberger W. Influence of essential and fatty oils on ciliary beat frequency of human nasal epithelial cells. American journal of rhinology. 2008; 22(2): 130-4. PMID: 18416967.

29) Giovannini D, Gismondi A, Basso A, Canuti L, Braglia R, Canini A, et al. Lavandula angustifolia Mill. Essential Oil Exerts Antibacterial and Anti-Inflammatory Effect in Macrophage Mediated Immune Response to Staphylococcus aureus. Immunological investigations. 2016; 45(1): 11-28. PMID: 26730790. doi: 10.3109/08820139.2015.1085392. PMID: 26730790.

30) Ozogul Y, Kuley E, Ucar Y, Ozogul F. Antimicrobial Impacts of Essential Oils on Food Borne-Pathogens. Recent patents on food, nutrition \& agriculture. 2015; 7(1): 53-61. doi: 10.2174/2212798407666150615112153. PMID: 26072990.

31) Prusinowska R, Smigielski K, Stobiecka A, Kunicka-Styczynska A. Hydrolates from lavender (Lavandula angustifolia)--their chemical composition as well as aromatic, antimicrobial and antioxidant properties. Natural product research. 2016; 30(4): 386-93. doi: 10.1080/14786419.2015.1016939. PMID: 25738904.

32) Georgiev YN, Ognyanov MH, Kiyohara H, Batsalova TG, Dzhambazov BM, Ciz M, et al. Acidic polysaccharide complexes from purslane, silver linden and lavender stimulate Peyer's patch immune cells 
through innate and adaptive mechanisms. International journal of biological macromolecules. 2017; 105(Pt 1): 730-40. doi: 10.1016/j.ijbiomac.2017.07.095. PMID: 28732735.

33) Gostner JM, Ganzera M, Becker K, Geisler S, Schroecksnadel S, Uberall F, et al. Lavender oil suppresses indoleamine 2,3-dioxygenase activity in human PBMC. BMC complementary and alternative medicine. 2014; 14: 503. PMID: 25515049, PMCID: PMC4301885.

34) Kiecolt-Glaser JK, Graham JE, Malarkey WB, Porter K, Lemeshow S, Glaser R. Olfactory influences on mood and autonomic, endocrine, and immune function. Psychoneuroendocrinology. 2008; 33(3): 328-39. PMID: 18178322, PMCID: PMC2278291.

35) Trellakis S, Fischer C, Rydleuskaya A, Tagay S, Bruderek K, Greve J, et al. Subconscious olfactory influences of stimulant and relaxant odors on immune function. Eur Arch Otorhinolaryngol. 2012; 269(8): 1909-16. doi: 10.1007/s00405-011-1876-4. PMID: 22159968.

36) de la Puerta R, Martinez-Dominguez E, Ruiz-Gutierrez V. Effect of minor components of virgin olive oil on topical antiinflammatory assays. Zeitschrift fur Naturforschung C. 2000; 55(9-10): 814-9. PMID: 11098836.

37) Liu Y, McKeever LC, Malik NS. Assessment of the Antimicrobial Activity of Olive Leaf Extract Against Foodborne Bacterial Pathogens. Frontiers in microbiology. 2017; 8: 113. PMID: 28210244, PMCID: PMC5288333.

38) Aparicio-Soto M, Sanchez-Hidalgo M, Rosillo MA, Castejon ML, Alarcon-de-la-Lastra C. Extra virgin olive oil: a key functional food for prevention of immune-inflammatory diseases. Food Funct. 2016; 7(11): 4492-505. doi: 10.1039/c6fo01094f. PMID: 27783083.

39) Martin-Pelaez S, Castaner O, Sola R, Motilva MJ, Castell M, Perez-Cano FJ, et al. Influence of PhenolEnriched Olive Oils on Human Intestinal Immune Function. Nutrients. 2016; 8(4): 213. PMID: 27077879, PMCID: PMC4848682.

40) Fito M, Gimeno E, Covas MI, Miro E, Lopez-Sabater Mdel C, Farre M, et al. Postprandial and short-term effects of dietary virgin olive oil on oxidant/antioxidant status. Lipids. 2002; 37(3): 245-51. PMID: 11942474.

41) Incani A, Serra G, Atzeri A, Melis MP, Serreli G, Bandino G, et al. Extra virgin olive oil phenolic extracts counteract the pro-oxidant effect of dietary oxidized lipids in human intestinal cells. Food Chem Toxicol. 2016; 90: 171-80. doi: 10.1016/j.fct.2016.02.015. PMID: 26911552.

42) Katsoulieris EN. The olive leaf extract oleuropein exerts protective effects against oxidant-induced cell death, concurrently displaying pro-oxidant activity in human hepatocarcinoma cells. Redox Rep. 2016; 21(2): 90-7. PMID: 26305493.

43) Rahmani AH, Albutti AS, Aly SM. Therapeutics role of olive fruits/oil in the prevention of diseases via modulation of anti-oxidant, anti-tumour and genetic activity. International journal of clinical and experimental medicine. 2014; 7(4): 799-808. PMID: 24955148, PMCID: PMC4057827.

44) Schillaci D, Napoli EM, Cusimano MG, Vitale M, Ruberto A. Origanum vulgare subsp. hirtum essential oil prevented biofilm formation and showed antibacterial activity against planktonic and sessile bacterial cells. Journal of food protection. 2013; 76(10): 1747-52. PMID: 24112575.

45) Bharti V, Vasudeva N, Sharma S, Duhan JS. Antibacterial activities of Origanum vulgare alone and in combination with different antimicrobials against clinical isolates of Salmonella typhi. Ancient science of life. 2013; 32(4): 212-6. PMID: 25364204, PMCID: PMC4213973.

46) Saeed S, Tariq P. Antibacterial activity of oregano (Origanum vulgare Linn.) against gram positive bacteria. Pak J Pharm Sci. 2009; 22(4): 421-4. PMID: 19783523.

47) Ksouri S, Djebir S, Bentorki AA, Gouri A, Hadef Y, Benakhla A. Antifungal activity of essential oils extract from Origanum floribundum Munby, Rosmarinus officinalis L. and Thymus ciliatus Desf. against Candida albicans isolated from bovine clinical mastitis. J Mycol Med. 2017; 27(2): 245-9. doi: 10.1016/j.mycmed.2017.03.004. PMID: 28454927.

48) Waller SB, Hoffmann JF, Madrid IM, Picoli T, Cleff MB, Chaves FC, et al. Polar Origanum vulgare (Lamiaceae) extracts with antifungal potential against Sporothrix brasiliensis. Med Mycol. 2018; 56(2): 225-233. doi: 10.1093/mmy/myx031. PMID: 28482071.

49) Bharti V, Vasudeva N, Kumar S. Anti-oxidant studies and anti-microbial effect of Origanum vulgare Linn in combination with standard antibiotics. Ayu. 2014; 35(1): 71-8. PMID: 25364204, PMCID: PMC4213973.

50) Ashraf A, Ashraf MM, Rafiqe A, Aslam B, Galani S, Zafar S, et al. In vivo antiviral potential of Glycyrrhiza glabra extract against Newcastle disease virus. Pak J Pharm Sci. 2017; 30(2): 567-72. PMID: 28650322 . 
51) Chakotiya AS, Tanwar A, Srivastava P, Narula A, Sharma RK. Effect of aquo-alchoholic extract of Glycyrrhiza glabra against Pseudomonas aeruginosa in Mice Lung Infection Model. Biomedicine \& pharmacotherapy. 2017; 90: 171-8. PMID: 28355591.

52) Sharma H, Yunus GY, Agrawal R, Kalra M, Verma S, Bhattar S. Antifungal efficacy of three medicinal plants Glycyrrhiza glabra, Ficus religiosa, and Plantago major against oral Candida albicans: A comparative analysis. Indian journal of dental research. 2016; 27(4): 433-6. PMID: 27723643.

53) Hejazi, II, Khanam R, Mehdi SH, Bhat AR, Moshahid Alam Rizvi M, Islam A, et al. New insights into the antioxidant and apoptotic potential of Glycyrrhiza glabra L. during hydrogen peroxide mediated oxidative stress: An in vitro and in silico evaluation. Biomedicine \& pharmacotherapy. 2017; 94: 265-79. PMID: 28763750.

54) Franceschelli S, Pesce M, Vinciguerra I, Ferrone A, Riccioni G, Patruno A, et al. Licocalchone-C extracted from Glycyrrhiza glabra inhibits lipopolysaccharide-interferon-gamma inflammation by improving antioxidant conditions and regulating inducible nitric oxide synthase expression. Molecules. 2011; 16(7): 5720-34. doi: 10.3390/molecules16075720. PMID: 21734629.

55) $\mathrm{Li} \mathrm{C}$, Eom T, Jeong Y. Glycyrrhiza glabra L. Extract Inhibits LPS-Induced Inflammation in RAW Macrophages. Journal of nutritional science and vitaminology. 2015; 61(5): 375-81. doi: 10.3177/jnsv.61.375. PMID: 26639845.

56) Brush J, Mendenhall E, Guggenheim A, Chan T, Connelly E, Soumyanath A, et al. The effect of Echinacea purpurea, Astragalus membranaceus and Glycyrrhiza glabra on CD69 expression and immune cell activation in humans. Phytotherapy research. 2006; 20(8): 687-95. PMID: 16807880.

57) Avicenna A. Canon of Medicine. Beirut: Dar ehya toras al-arabi; 2005: 16.

58) Jorjani SI. zakhireh Kharazmshahi. 1 ed. Qom: Ehya'e tibbe tabiee.

59) Aghili MH. Makhzan-al-Advia. In: Rahimi R, Shams-Ardekani MR, Farjadmand F, editors. Tehran, Iran: Tehran University of Medical Sciences; 2009: 143,441,481.

60) A'azam khan Chashti M. The Grater Exir. 1 ed. Tehran: Research Institute for Islamic and Complementary Medicine; 2008: 121.

61) Ibne-Nafis. A'shshamel fes senaa'tot tebbiah. 1 ed. Tehran: Research Institute for Islamic and Complementary Medicine. 2000: 267. 